\title{
Publicar ou perecer: a esfinge do produtivismo acadêmico
}

Janete Luzia Leite

Universidade Federal do Rio de Janeiro (UFRJ)

\section{Publicar ou perecer: a esfinge do produtivismo acadêmico}

Resumo: Este artigo trata da reestruturação das condições e processos de trabalho dos professores no ensino superior hodiernamente, que introduz a lógica gerencial nas atividades docentes. Mostra como esta nova lógica adoece o professor física e mentalmente. Para tanto, analisa as últimas transformações no mundo do trabalho e como estas influenciaram diretamente a Reforma Universitária empreendida pelos governos do Partido dos Trabalhadores. Investiga também o atendimento existente nas universidades públicas brasileiras (2016), bem como entrevista docentes de vários cursos e universidades (2015-2016) a respeito das transformações ocorridas no seu labor. O resultado demonstra que a intensificação e precarização estão presentes em todo o trabalho acadêmico atualmente e que os professores têm consciência de que seu trabalho, hoje, passou a ser a fonte de agravos à saúde física e mental. Entretanto, recusamse a procurar auxílio, para não serem estigmatizados por não suportarem as novas formas do trabalho docente nas universidades.

Palavras-chave: Intensificação do trabalho docente. Produtivismo. Gerencialismo. Adoecimento.

\section{Publish or perish: the puzzle of academic productivism}

Abstract: This paper describes the restructuring of the conditions and procedures for the current work of professors in higher education, which introduces management logic to teaching. It shows how this new logic causes professors to fall physically and mentally ill. For this purpose, it analyzes the recent transformations in the labor world and how they directly affect the University Reform undertaken by the presidential terms of the Workers' Party. The service currently offered in Brazilian public universities (2016) was investigated, and professors from various courses and universities (2015-2016) were interviewed about the transformations that have occurred in their work. The result shows that intensification and deterioration of work are currently present throughout the academic work and that teachers are aware that their work, nowadays, has become a source of physical and mental diseases. However, they refuse to seek for help in order not to be stigmatized because they did not tolerate the new ways of teaching work in universities.

Keywords: Intensification of teachers' work. Productivism. Managerialism Occupational and work-related diseases. 


\section{Introdução}

No processo de transformação-adaptação que o sistema capitalista realiza historicamente, algumas mudanças se repetem. Para a sobrevivência e a expansão do sistema, estas mudanças atuam tanto nas formas de exploração do trabalho, o mundo do capital - incluindo aí a criação e utilização de novas tecnologias -, quanto nas características de reprodução ideológica e material da força de trabalho. Contemporaneamente, este processo tem como chão uma crise cronificada, que se manifesta através de um pico de exasperação do movimento da sociedade; o tecido social se crespa e está quase rompido. Está-se falando de um tensionamento que vai aumentando lentamente, até tornar-se natural. A crise se banalizou. As resultantes mais visíveis encontram eco nos movimentos dos trabalhadores (uma enorme dominância corporativista) e no conjunto do movimento social (uma atomização e uma pulverização absolutas). Simplesmente se joga na natural fragmentação e se transfere para organismos da chamada sociedade civil o ônus de projetos estrategicamente dirigidos pelo Estado, entrando aí um soberano desprezo pelo último (LEITE, 2010). Dessa forma, o mercado começa a demarcar as fronteiras dos Estados e lhes exige que facilitem seu livre movimento, intervindo somente nas áreas não mercantilizáveis (THERBORN, 2002). Tem-se, assim, por um lado, a redução e focalização da ação estatal para aqueles casos mais imediatos e urgentes (consubstanciando o princípio da subsidiariedade do Estado); e, por outro lado, a privatização e a consequente transformação em mercadoria dos serviços sociais a serem adquiridos no mercado pelo "cidadão consumidor" (MOTA, 2005).

Paulatinamente, as experiências de condução política neoconservadoras retiram da órbita do Estado as funções de proteção social consideradas ineficientes do ponto de vista mercantil, buscando outros responsáveis para sua produção e administração. Desta forma, a crise e a crítica do Estado permitiram o avanço da tese liberal conservadora no campo das políticas sociais, reforçando o processo de reforma do Estado mediante a justificativa da necessária redução do setor público, o que significa privatização. Há uma expansão mundial da desproteção social. O desemprego estrutural (fomentado principalmente pela reestruturação produtiva) e o aumento da pobreza e da miséria sociais (causados pela conjugação de desemprego, retirada de direitos e enxugamento de políticas sociais) provocam a ascensão de uma franja social que começou a ser considerada desnecessária ao capital, ou seja, não se inseriria na economia - seja ela formal ou informal. Esta franja social manifesta-se por meio de uma horda de neofamélicos e neomiseráveis, que não só colocam em xeque as maravilhas propaladas pelos arautos do neoliberalismo, como também ameaçam a sua continuidade, pois são a prova cabal da falência do novo modelo. São estes os segmentos mais pauperizados da sociedade e, não raro, aqueles também mais historicamente marginalizados.

Assim, a atual conjuntura conduz à hegemonia do neoliberalismo, tanto em nível ideológico quanto prático. É notório também que a ofensiva neoliberal exige a reconfiguração do Estado. A conjugação dos elementos necessários a essa reconfiguração implica em uma nova sociabilidade, que se inicia com o redimensionamento das classes trabalhadoras. Novamente, a subjetividade dos trabalhadores precisa ser capturada e reconfigurada a partir de um padrão de individualismo no qual a luta de classes deve ser obscurecida, dando lugar a um estranhamento interclasse. Para tanto, um dos caminhos mais eficazes é a reconfiguração do mundo do trabalho por meio de reformas no sistema de educação. Entretanto, estas reformas não afetam somente os ditos currículos ou pedagogias do ensino, afetam também aqueles que trabalham na área da educação, causandolhes transtornos físicos e mentais.

No que se refere aos docentes, pouca atenção tem sido dada aqueles envolvidos com a educação superior. Quando se trata das consequências das transformações ocorridas hodiernamente no fazer profissional dos professores, a esmagadora maioria das pesquisas e textos ignora o que ocorre entre os docentes universitários. Aliás, este segmento desconhece o que vem acontecendo no interior de sua própria categoria profissional, haja vista não só a ausência de estudos, mas também de dados sobre a saúde do docente do ensino superior nas Unidades de Saúde das universidades. Contudo, os afastamentos, raras vezes oficializados, decorrentes de estresse, que constantemente encobrem o alcoolismo, a dependência química, a síndrome do pânico e a síndrome de Burnout, dentre outros transtornos, lombalgias, gastrites e depressão; ou mesmo a utilização de ansiolíticos, antidepressivos ou medicamentos conhecidos como tarja preta, estão experimentando um ascenso acelerado entre os professores universitários.

É destas ocorrências que o estudo em tela irá tratar. Partiremos do pressuposto de que as transformações no mundo do trabalho, quando transportadas para o Sistema de Educação, consubstanciam-se na Reforma da Educação que foi empreendida pelos dois governos do Partido dos Trabalhadores (PT), o de Lula da Silva e o de Dilma Rousseff. Esta Reforma, no seu traçado universitário, engendra um fazer profissional cujo traço mais marcante é a introdução da lógica gerencial nas universidades públicas, aportando para este universo a competitividade, o produtivismo, a intensificação e a precarização do trabalho docente, que provocam o que Sguissardi e Silva Júnior (2009) denominam de "indissociação tempo-espaço da vida acadêmica e familiar e pessoal". 
O resultado mais visível é a implosão deste trabalhador. A fim de corroborar esta premissa, buscaremos estabelecer a relação entre os principais eixos da Reforma Universitária - REUNI, novas regras para a pós-graduação - e os transtornos causados à saúde dos docentes universitários. Para tanto, procedemos a uma ampla revisão de literatura sobre produtivismo acadêmico; e intensificação do trabalho e adoecimento dos docentes. Paralelamente, em virtude das várias palestras realizadas sobre o tema, pudemos entrevistar os docentes ${ }^{1}$ de várias universidades, localidades, e disciplinas a respeito das transformações ocorridas em seu fazer profissional. Todos concordaram livremente em serem entrevistados, desde que suas identidades fossem resguardadas.

Daremos como suposto o conhecimento acerca das metamorfoses operadas no mundo do trabalho, posto que sobejamente conhecidas e disponíveis em trabalhos de envergadura, e passaremos diretamente à análise das questões supra elencadas.

\section{A reforma universitária sob os governos do partido dos trabalhadores ${ }^{2}$}

No Brasil, o pioneirismo do Partido dos Trabalhadores (PT), materializado na legitimidade conferida nas urnas, em outubro de 2002, à candidatura de Lula da Silva, não impediu uma política de aprofundamento das medidas de caráter neoliberal - notadamente no que diz respeito à continuidade de uma política macroeconômica absolutamente favorável ao capital financeiro - tão cara aos governos anteriores, aos quais o PT, agora no governo, criticou sempre exacerbada e enfaticamente (PETRAS, 2004; LEITE, 2006). O PT chega, portanto, ao governo, da mesma forma como se executa uma melodia ao violino: segura com a mão esquerda e toca com a direita. É notório que, longe de se contrapor à maré montante neoliberal, Lula da Silva realiza um aprofundamento das políticas de interesse do grande capital - nacional ou não -, buscando, não obstante, apresentar-se de forma diferenciada de seu antecessor. Utilizando-se da aura de nordestino retirante ex-líder sindical, o Presidente Lula da Silva adoça a pílula amarga das ações governamentais, que garantem enormes lucros para o grande capital (bancos, indústrias, agronegócios etc.), com a implementação de políticas sociais que vão de encontro àquelas em curso durante os anos de hegemonia do modelo de Welfare State dos chamados trinta anos gloriosos, posto que assumem um caráter francamente focalista, pontual, fragmentado e, principalmente, descontínuo. Receitas, ainda, daquelas agências do capital imperialista, com vistas a amortecer reações contrárias e dar a impressão de melhoria das condições de vida a parcelas da população mais carente das ações do Estado.

Reformas que não medraram no governo de Fernando Henrique Cardoso (FHC) foram encaminhadas açodadamente no primeiro mandato do governo petista. Assim é que tivemos a implementação de uma (contra)reforma da Previdência do setor público (2003) e o início das (contra)reformas da Educação (travestida de reforma universitária em 2004), Sindical e Trabalhista, que só não lograram êxito total devido ao escândalo que atingiu em cheio a base governista, em junho de 2005, mas que foram retomadas após sua segunda vitória eleitoral. Além disso, houve a

\section{O relato mais comum é a}

ausência de descanso nos finais
de semana, feriados e férias e o
afastamento da família e dos
amigos.
implementação de um feixe de medidas que complementam a (contra)reforma do Estado iniciada por FHC: as políticas sociais públicas tornam-se cada vez mais focalizadas e pontuais, parametradas mercadológica e empresarialmente por critérios de racionalização, custo-benefício e produtividade, isso quando não simplesmente privatizadas, ou entregues a organizações da sociedade civil para as quais o Estado desvia recursos sem maiores controles. Some-se a isso o fato de que, além de não divulgar quantos postos de trabalho foram extintos, e muito menos que a média salarial do trabalhador diminuiu, o governo ainda propala a criação de três milhões de novos empregos, ciente da impossibilidade prática dessa aferição, e o fracasso de programas como o Primeiro Emprego, cujos recursos foram totalmente desviados para o Bolsa-Família, carro-chefe da reeleição de Lula da Silva e posterior eleição (e também reeleição) de Dilma Rousseff). Aliás, no governo Lula da Silva (bem como no de sua sucessora Dilma Rousseff), os programas sociais governamentais se transformam na moeda de troca, evidentemente amesquinhada, para tentar conter o agravamento da questão social, o qual se voltaria não só contra Lula da Silva, mas também contra o conjunto da burguesia e seus enormes lucros atuais. Um assistencialismo dos mais ordinários foi cuidadosamente administrado à população, ao mesmo tempo em que as políticas macroeconômicas de corte o mais ortodoxo possível a empobrecia. Produziu-se, assim, uma química altamente apassivadora de prováveis conflitos advindos de uma horda de miseráveis (DIAS, 2006). 
No que concerne à educação, depois de aprovados, por um sem-número de MP e decretos, os pilares centrais da Reforma Universitária, o governo preparou os ajustes finais (propalando os "ganhos" que adviriam com a Universidade Aberta e a Universidade Nova), transformando, assim, toda a Educação brasileira (notadamente a de nível superior) em um grande nicho para as empresas (sobretudo as estrangeiras) investirem, dela retirando o que ainda restava de ensino, pesquisa e extensão de qualidade e socialmente referenciada. Tem-se, assim, a consolidação, acelerada e fragmentada, de políticas educacionais - como, de resto, de todas as políticas sociais - consistentes com as agendas dos organismos internacionais para os países "pobres" ou "do terceiro mundo" ou "emergentes" ou "de baixa renda" ou "periféricos" - não importa o jargão, a geopolítica é a mesma. Colocando em foco o arcabouço conceptual, as diretrizes operacionais e as estratégias de pressão do Banco Mundial (BM), envoltas em proposições místicas e mistificadoras como "Combate à Pobreza", "Educação para Todos", "Metas de Desenvolvimento do Milênio", "Economias do Conhecimento" e outras de semelhante jaez, esse caminho tem sido trilhado, desde a primeira metade dos anos 1990, com a adesão dos diferentes governos brasileiros do período (LEITE, 2008). É bem verdade que alguns deslocamentos de ênfase, gerados, principalmente, por crescentes manifestações de descontentamento por parte dos países-clientes, têm sido observados, passando a ilusória impressão de que o novo discurso do Banco é, de fato, novo, ou que os documentos de avaliação e orientação, de 1993 a 1998, têm diferenças substantivas por comparação com o conjunto de publicações de 1999 em diante (WORLD BANK, 1999, 2005).

No que tange à Reforma Universitária, propriamente dita, o primeiro registro a fazer é que as referências acima citadas, e outras tantas, integram, de formas variadas, a letra do PL $n^{\circ} 7.200 / 2006$ ou, na estratégia governamental de fragmentação, integram outros instrumentos legais (Diretrizes Curriculares Nacionais (DCN), Lei de Inovação Tecnológica, Sistema Nacional de Avaliação da Educação Superior - Sinaes, etc.) que, no conjunto, compõem a reformatação da educação superior, como parte das pressões exercidas não somente pelo Banco Mundial, como também pela Organização Mundial do Comércio (OMC). Na linha assistencialista, compensatória, o Programa Universidade para Todos (PROUNI), deve ser sempre lembrado como parte dessa estratégia; sua crescente demanda reforça o acordo de compra e venda de vagas, a transferência de recursos públicos para o setor privado, e a mercadorização do direito à educação. Na sequência, a Política de Assistência Estudantil coroa as novas formas de assistencialização, sob a falácia do acesso das populações mais empobrecidas ao estudo universitário.

A educação à distância $(\mathrm{EaD})$ tem visível centralidade nas políticas do Ministério da Educação e Cultura (MEC), para diferentes níveis e modalidades de ensino e situações educacionais, podendo-se antever um quadro de nefastas consequências para a educação brasileira. O Plano Nacional de Educação (PNE - de lavra completa do governo de FHC) apresenta, em suas diretrizes e metas, uma variedade de usos e abusos da educação à distância. Com isso, o MEC pretende ampliar a oferta de educação superior, de modo a alcançar, em dez anos, $40 \%$ das vagas nas Instituições de Ensino Superior públicas, como previsto no PNE, sem maiores preocupações quanto a investimentos nas instituições. A criação e o funcionamento da Universidade Aberta do Brasil, instituição não gratuita, de direito privado, confirma essas afirmativas como confirma, também, ao lado de inúmeras outras iniciativas, a opção do governo brasileiro por submeter-se às pressões da $\mathrm{OMC}$, no bojo do Acordo Geral de Comércio de Serviços - AGCS (ou GATS). Essa abertura do mercado brasileiro ao comércio transnacional de educação caminha ao encontro dos interesses daqueles que, mundo afora, estão ávidos pelo atraente mercado, para o ensino superior no Brasil.

O Reuni foi a coroação da Reforma Universitária levada a cabo ainda sob a batuta de Lula da Silva, proclamando objetivos gerais que nunca foram cumpridos (em parte devido ao cerco financeiro ao programa) ${ }^{3}$. Com exceção daquelas em que medidas judiciais determinaram sua sustação, as universidades federais, em massa, aprovaram o Reuni: com maior ou menor truculência e ações repressoras, com legitimidade questionável ou não, e independentemente dos eufemismos usados pelas instituições para nomear seus projetos, foi aberta a temporada de trocas de promessas de novos recursos por uma completa transformação de muitas dessas instituições em fábricas de diplomas, com sérias implicações futuras quanto à qualidade do seu ensino, da sua pesquisa e da sua extensão. Além disso, a tão divulgada extensão dos campi universitários, implicou em uma matriz avaliativa de distribuição de (parcos) recursos vinculada diretamente ao aumento de ingressos discentes e de carga horária docente sem que houvesse aumento na contratação, ou, quando muito, uma contratação por tempo determinado (professor substituto) e do Banco de Professor Equivalente ${ }^{4}$ (LEITE, 2008).

As exigências para os professores que estão inseridos na pós-graduação também foram exponenciadas, diversificadas e dicotomizadas:

Na prática cotidiana, os professores-pesquisadores defrontam-se claramente com duas realidades: uma, a graduação, que, apesar da presença, de crescente teor regulatório, do sistema de avaliação (SINAES), move-se, prioritariamente, sob os ditames da autonomia institucional; outra, a pós-graduação, que, de forma 
cada vez mais evidente, estrutura-se e funciona sob os ditames heterônomos da Capes, coadjuvante pelo CNPq, Finep e outros órgãos externos à instituição (SGUISSARDI; SILVA JÚNIOR, 2009, p. 73).

Um exemplo claro são as Bolsas de Produtividade $(\mathrm{CNPq})$, que indubitavelmente trazem status, mas implicam em altos custos pessoais para sua manutenção. Isto porque os critérios são, cada vez mais, mensurados quantitativamente, enquanto o número de bolsas diminui ou estanca. A primeira consequência é o abandono das atividades na graduação, notadamente o ensino (uma vez que os estudantes de Iniciação Científica (IC) ainda são necessários para os projetos de pesquisa). Conforma-se um novo tipo de professor, cujo patamar de qualificação e investimentos leva em conta, quase que exclusivamente, a pesquisa.

Depreende-se, portanto, que a Reforma Universitária incide liminarmente sobre a morfologia do docente do ensino superior. Mas suas sequelas mais (in)visíveis desbordam largamente as questões atinentes à institucionalidade.

\section{Repercussões para a saúde do docente: publish or perish}

No todo, as micropolíticas que enformam a Reforma Universitária terminam por gerar uma intensificação no trabalho docente, que se materializa em um ambiente laboral/profissional marcado por competitividade e pressões pelo desempenho quantitativo e o cumprimento de metas (gerencialismo). Isto, aliado à compressão salarial, à ampliação das exigências de produção e produtividade no campo da pesquisa e pós-graduação (prazos, bolsas, Editais, participação em eventos científicos etc.), ao produtivismo acadêmico (publish or perish).

Esquemática e sucintamente, a rotina intensificada de um professor universitário atualmente pode ser assim representada:

- Aulas: maior exigência sobre a pós-graduação

- Administração institucional: conselhos, colegiados etc.

- Bancas: mestrado; doutorado; concursos

- Orientações de mestrado: acarretando na diminuição do tempo de conclusão

- Doutorado: orientações on-line e similares

- Iniciação Científica

- Monitoria

- Estagiários

- Especialização

- E-mails: passar, responder

- Lançamento de graus e frequência (enxugamento do quantitativo de técnicos-administrativos)

- Relatórios, pareceres: pesquisa, extensão, revistas

- Projetos: "empreendedorismo"; competição; material de trabalho e pesquisa privados; agregação monetária ao docente e à instituição

- Artigos (papers): Qualis

- Preparação de aulas: graduação e pós

- $\quad$ Correção de trabalhos e provas: graduação e pós

Esta rotina desborda largamente a carga horária diária/semanal de trabalho e invade a residência dos docentes, tomando-lhes os dias de descanso e as férias. Esta intensificação desmesurada, de acordo com Meis et al. ( 2003), propicia a ocorrência de:

- Aumento do consumo de álcool, drogas e tabaco - provocando doenças crônicas, principalmente cardiovasculares e respiratórias.

- Depressão - abuso de ansiolíticos, hipnóticos e neurolépticos. Suicídio.

- $\quad$ Síndrome de Burnout - resultado de um prolongado processo de tentativas de lidar com determinadas condições de estresse, sem sucesso.

- Assédio moral (psicoterrorismo ou acoso ou bullying) - um processo de violência psicológica extremado contra o trabalhador, que pode ter relação direta com danos à sua saúde.

$\mathrm{O}$ aumento no consumo de álcool e as síndromes depressivas, mesmo quando percebidas, rapidamente são ocultadas pelos docentes e seus colegas de labor. No máximo, comentários são tecidos, in off, a respeito: “fulano está ‘derrubando' uma garrafa por noite”; ou "cicrano está tomando 'tarja preta"”. Estas ocorrências são de difícil caracterização como sequelas de uma intensificação brutal do trabalho, com a sua desumanização paulatina. Não obstante, trata-se de manifestações silenciosas. Porém, o efeito mais deletério destas mazelas é a negação, por parte dos docentes, de que elas existem. Mas é necessário sinalizar que estas manifestações patológicas, derivadas das condições de trabalho, só aparecem como tal ou como doenças ocupacionais após o 
advento da reestruturação produtiva, ou seja, trata-se de novas doenças, mesmo que tragam em si sintomas de antigas. Ademais, a intensa psicologização que caracteriza estas patologias também é um impeditivo para o seu diagnóstico, uma vez que são absolutamente subjetivas.

Em um mundo no qual a resiliência tornou-se uma espécie de qualificativo de seres superiores, aliado ao fato de que qualquer afastamento - por menor que seja - do docente das suas atividades (é mister reiterar: a ênfase é na pós-graduação), produz uma perda de oportunidades de projetos, produções (de artigos, livros, redes) de difícil (ou lentíssima) recuperação. Desta forma, o professor, cada vez mais, acostuma-se a suportar o fardo do cansaço e dos dias superdimensionados, como um incansável Sísifo moderno.

Mesmo assim, é necessário fazer uma caracterização, a fim de que se possa apreender minimamente, o que já se configura como uma espécie de "epidemia" entre os docentes. Podemos, então, elencar alguns antecedentes mais gerais, no enorme leque de processos catalisadores:

- transformações nos critérios das agências de fomento a pesquisas - exponenciação da exigência de publicações, bem como orientações (IC, monitoria, graduação e pós-graduação - lato e stricto sensu) e participação em bancas de avaliação de trabalhos científicos e pareceres. O conjunto destes (e outros) é determinante para a oportunidade de financiamento de projetos e/ou bolsas, que minguam cada vez mais;

- aumento do número de estudantes sem a contrapartida quantitativa de funcionários e docentes;

- $\quad$ enxugamento do contingente de funcionários administrativos, cujas funções são repassadas para os docentes;

- majoração das exigências de aprimoramento intelectual;

- incremento das exigências quanto à qualidade do trabalho;

- exigência de maior comprometimento docente com a organização para atender às múltiplas demandas burocráticas (comissões, reuniões, relatórios etc.);

- $\quad$ alto nível de competição, a fim de alcançar pontuações que destaquem a produção docente como excepcional, auferindo-lhe incentivos financeiros e status acadêmico.

Mas seus fatores desencadeantes podem ser observados em uma íntima relação com os antecedentes (LEITE, 2015), tais como sobrecarga de trabalho e/ou ocupação pouco estimulante; pouca ou nenhuma participação na tomada de decisões; falta de meios para realizar as atividades; excesso de burocracia; perda de identidade com o que realiza; e não reconhecimento pelo bom trabalho, mas há duras críticas quando algo sai errado.

A utilização da palavra "aumento" e seus sinônimos denota bem que a exacerbação do trabalho é a fonte primordial das atuais doenças e manifestações patológicas que acometem os docentes. Em sua manifestação, em geral, encontram-se três dimensões, que podem aparecer associadas, mas são independentes:

- Esgotamento Emocional: ausência ou carência de energia, acompanhada de um sentimento de esgotamento emocional;

- Falta de Realização Profissional: sentimento de inadequação pessoal e profissional. Há uma tendência de o trabalhador se autoavaliar de forma negativa;

- Despersonalização: endurecimento afetivo ou insensibilidade emocional. Tratar alunos e colegas como objetos, "coisificar" a relação.

Quando se conversa com docentes a respeito dos antecedentes, fatores desencadeantes e manifestações de desconfortos físicos ou doenças propriamente ditas, é perceptível um certo assentimento, como um check list. Alguns chegam a expressar que "eu sinto tudo isso", mas encaram como normal, imutável. Foram justamente estes depoimentos informais que nos levaram a sistematizar um roteiro de entrevista que pudesse subsidiar nossas reflexões.

Além disso, o ataque psicológico reiterado e sistemático também se tornou frequente no trabalho docente. Seu perfil consiste na concretude do ambiente de trabalho, onde o estabelecimento de rótulos ou perfis poderá ensejar humilhação, degradação, desvalorização daqueles que, mesmo produtivos, sejam tidos como de menor importância quando em cotejo com outros, os que possuem o "perfil" desejado. Este tipo de prática não se restringe ao âmbito individual: quando um é humilhado, todos os outros que se identificam com ele sentemse também desprezados e ameaçados, percebendo-se como "a próxima vítima".

$\mathrm{O}$ que se nota, no cotidiano dos docentes, na atualidade, é uma mistura de sintomas que, em geral, desencadeiam nosologias que podem (e, em geral, são) confundidas com outras, de etiologia difusa. Os sintomas mais comuns manifestam-se como (GONZÁLEZ; DOMINGUEZ, 2009): síndromes de ansiedade; depressão, incluindo apatia, insônia, pensamento introvertido, problemas de concentração, perda de interesse por coisas ou situações que antes lhe despertavam, insegurança, falta de iniciativa, melancolia; mudanças de humor (ciclotimia); e irritabilidade (distimia). Evoluindo para manifestações físicas e comportamentais de: hipertensão arterial; ataques de asma brônquica; úlceras estomacais; enxaqueca; perda de equilíbrio (labirintite 
ou síndrome de Menière); torcicolos; lumbagos; queda de cabelo (alopecia); dores musculares e/ou articulares de origem tensional; estresse; agressividade (consigo ou com outras pessoas); transtornos alimentares; aumento do consumo de álcool e/ou drogas; aumento do tabagismo; disfunção sexual; isolamento social; e suicídio.

Assim, ao conversarmos com docentes por ocasião do proferimento de palestras a respeito deste tema, pudemos esboçar um quadro que, apesar de pequeno, é de tal forma contundente que se torna impossível de ignorar. O nosso primeiro passo foi pesquisar, no sítio das 109 universidades públicas brasileiras - federais e estaduais - a existência de unidades de atendimento aos docentes. Das 109 universidades pesquisadas, somente 17 possuem, em suas páginas digitais, algum tipo de link para serviços/departamentos de atendimento à saúde dos docentes ou mesmo estudos a respeito. Destas, 16 se localizam no eixo sul/sudeste, e uma no nordeste do Brasil. Somente quatro informam algum tipo de atendimento aos agravos de saúde decorrentes das condições de trabalho dos docentes. Dentre essas quatro universidades, três localizam-se no sul do país, e uma no nordeste. Somente uma é universidade federal.

Quadro 1 - Informações nas páginas virtuais das universidades públicas brasileiras sobre a existência de Unidades de Atendimento à Saúde dos Docentes - 2016

\begin{tabular}{|c|c|c|c|c|c|c|c|c|c|c|}
\hline \multicolumn{11}{|c|}{ Universidades Públicas Pesquisadas (N=109) } \\
\hline \multirow{2}{*}{$\begin{array}{l}\text { Informações procuradas } \\
\text { Regiões do Brasil }\end{array}$} & \multicolumn{5}{|c|}{ Federais } & \multicolumn{5}{|c|}{ Estaduais } \\
\hline & $\mathrm{N}$ & $\mathrm{Ne}$ & $\mathrm{CO}$ & $\mathrm{Se}$ & $\mathrm{S}$ & $\mathrm{N}$ & $\mathrm{Ne}$ & $\mathrm{CO}$ & $\mathrm{Se}$ & $\mathrm{S}$ \\
\hline $\begin{array}{l}\text { Páginas virtuais com link para serviços de aten- } \\
\text { dimento a funcionários }\end{array}$ & - & 01 & - & 02 & 03 & - & - & - & 04 & 07 \\
\hline $\begin{array}{l}\text { Algum tipo de atendimento a agravos à saúde } \\
\text { decorrentes das condições de trabalho }\end{array}$ & - & 01 & - & - & - & - & - & - & 02 & 01 \\
\hline
\end{tabular}

Fonte: Elaborado pela autora.

Foram entrevistados 55 docentes. Destes, 24 eram do sexo feminino e 31 eram do sexo masculino. Todos estavam na faixa etária compreendida entre 32 e 60 anos de idade 5 .

Participaram das entrevistas representantes de sete categorias profissionais, sendo cinco relacionadas às Ciências Humanas e Sociais e duas às Ciências da Saúde (Direito = 6; Educação = 9; Enfermagem = 10; História = 3; Medicina = 8; Serviço Social = 15; e Teatro =4) de várias universidades, desde que federais ou estaduais, conforme pode ser verificado no Gráfico 1, infra).

\section{Gráfico 1 - Cursos aos quais estão vinculados os docentes entrevistados - 2015-2016}

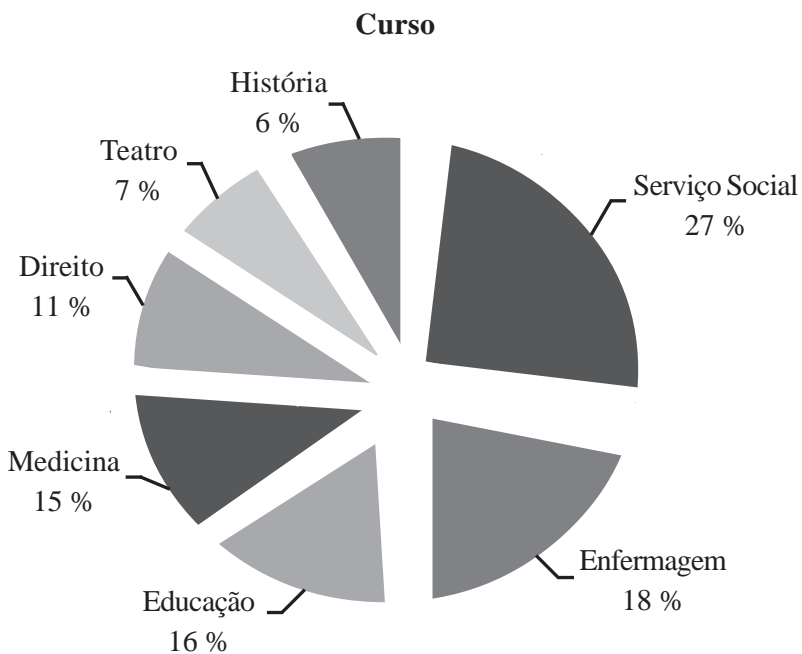

Fonte: Elaborado pela autora. 
As mudanças ocorridas no processo de trabalho docente impactam sobremaneira a saúde - todos os entrevistados (mesmo os ligados somente à graduação) sentem que seu trabalho foi intensificado. O relato mais comum é a ausência de descanso nos finais de semana, feriados e férias e o afastamento da família e dos amigos.

No que tange aos docentes que ainda não estão na pós-graduação, os mesmos sentem que estão "carregando o piano" dos que já estão nesse nível de ensino, pois o encargo das aulas e orientações de Trabalhos de Conclusão de Curso, além de grande parte da Extensão, recaem sobre eles. Já aqueles que estão na pósgraduação ressentem-se por terem que agregar orientações da graduação e pós às atividades de pesquisa, publicação e participação em eventos sem recursos humanos e financeiros. A já citada "concorrência" e o trabalho isolado (individualismo) são os fatores de maior estresse entre os docentes da pós-graduação.

No que diz respeito à saúde, os relatos explicitam insônia, fadiga crônica e enxaquecas ou aparecimento de distúrbios neurológicos ("branco", troca de palavras). Raros referem aumento no uso de álcool (mas são enfáticos ao reconhecerem isso em "outros colegas") e drogas. Mas, em sua esmagadora maioria, dizem que é inevitável que o trabalho ganhe esta intensidade e que os agravos desta decorrem da sua própria falta de organização. Ou seja, não só já introjetaram este ritmo (culpando-se por não saberem lidar com ele) como também já o naturalizaram. Não vislumbram outra forma de trabalhar. Nenhum conhece algum serviço em sua universidade ao qual recorrer. Entretanto, informam que dificilmente o procurariam, caso exista, pois sentem receio de serem estigmatizados ou de terem que se afastar, o que, no caso dos docentes inseridos na pósgraduação, representa, muitas das vezes, a sua saída daquele espaço.

\section{Considerações finais}

As implicações das novas formas de trabalho docente são severas, levando desde o consumo de ansiolíticos até o suicídio. A aferição e o diagnóstico das patologias aqui tratadas são extremamente difíceis. Entretanto, enquanto o docente continuar reconhecendo seus sintomas, mas tratando-os como algo natural ou inevitável, pouco poderá ser feito. Isso é o resultado de uma equação simples: o individualismo e a competição adquirem proeminência e tendem a ser naturalizados.

Não obstante, a nova conformação assumida pela universidade, cujo modelo gerencial, produtivista e de alcance de metas é o mais destacado, estabelece uma relação economia-tempo, de difícil enfrentamento, posto que:

Trata-se do tempo da economia determinando o tempo da universidade, o que transforma a prática universitária cotidiana e vai construindo nova concepção de universidade, sem resistência e com muita adesão passiva, em razão da forma como os professores encarem o processo de produção acadêmico-cientifico, em geral sem crítica do modo como se organiza essa atividade (SGUISSARDI; SILVAJÚNIOR, 2009, p. 166).

Com isso, o tempo-espaço entre a vida acadêmica e a vida pessoal são condensados em um só. Tornase imperativo que estas patologias sejam melhor elucidadas e discutidas entre os docentes, sob a pena de perderem-se profissionais valiosos. Para isso, antes de mais, é necessário recuperar a universidade como locus público, onde se constroem as mais ricas relações sociais, justamente porque possui como matéria-prima todas as expressões da ciência, da arte e da cultura. Por isso, não pode continuar submetida (assim como seus docentes) à lógica dominante do capital, e sim ser propulsora da reflexão crítica e da emancipação humana.

\section{Referências}

SINDICATO NACIONAL DOS DOCENTES DAS INSTITUIÇÕES DE ENSINO SUPERIOR - ANDES-SN. As Novas Faces da Reforma Universitária do Governo Lula e os Impactos do PDE sobre a Educação Superior. Cadernos ANDES, Brasília, n. 25, ago. 2007. BRASIL. Conselho Nacional de Saúde. Resolução n. 510, de 07 de abril de 2016. Ética em Pesquisa para Ciências Humanas e Sociais. DF, 2016. Disponível em: <http://conselho.saude.gov.br/resolucoes/2016/Reso510.pdf>. Acesso em: 18 mar. 2017.

DIAS, E. F. Política Brasileira: embate de projetos hegemônicos. São Paulo: Instituto José Luís e Rosa Sundermann, 2006.

GONZALEZ, S. T.; DOMINGUEZ, J. F. P. El trabajador universitário: entre el malestar y la lucha. Educação Social, Campinas, v. 30, n. 107, p. 373-387, mai./ago. 2009.

LEITE, J. L. Produtivismo acadêmico e adoecimento docente: duas faces da mesma moeda. In: FERREIRA, A. et al. (Orgs.). Precarização do Trabalho e Saúde Docente nas Universidades Públicas Brasileiras. Fortaleza: EdUECE, 2015. p. 72-79.

. "Questão Social” e Políticas Sociais Brasileiras: o Governo Lula em pauta. Revista Temas \& Matizes, Cascavel, v. 9, n. 17, p. 87-102, 2010.

. Da esperança ao desencanto: a "questão social” e as politicas públicas no governo Lula da Silva. In: ENCONTRO NACIONAL 
DE PESQUISADORES EM SERVIÇO SOCIAL, 11, 2008, São Luís/MA. Anais... São Luís/MA: UFMA, 2008.

. Globalizacion y Exclusion: las politicas sociales brasileñas como paradigma. In: CONGRESO MUNDIAL DE ESCUELAS DE TRABAJO SOCIAL, 33, 2006, Santiago, Chile. Anais... Santiago, Chile, 2006.

MEIS, L. et al. The growing competition in Brazilian science: rites of passage, stress and burnout. Brazilian Journal of Medical and Biological Research, Ribeirão Preto, v. 36, n. 9, p. 1135-1141, set. 2003.

MOTA, A. E. Cultura da Crise e Seguridade Social. São Paulo: Cortez, 2005.

PETRAS, J. Brasil y Lula - año cero. In: PETRAS, J. et al. (Orgs.). América Latina: imperialismo, recolonización y resistencia. Quito, Ecuador: Ediciones Abya-Yala, 2004. p. 111-194.

SGUISSARDI, V.; SILVA JUNIOR, J. R. Trabalho Intensificado nas Federais: pós-graduação e produtivismo acadêmico. São Paulo: Xamã, 2009.

THERBORN, G. Dimensões da globalização e a dinâmica das (des)igualdades. In: GENTILI, Pablo (Org.). Globalização excludente: desigualdade, exclusão e democracia na nova ordem mundial. Petrópolis, RJ: Vozes, 2002. p. 63-95.

WORLD BANK. Human Development Network. Education Sector Strategy. Washington, D.C.: The International Bank for Reconstruction and Development / The World Bank, 1999. <http://siteresources.worldbank.org/EDUCATION/Resources/ESSU/ education_strategy_1999.pdf>.Acesso em: 18 mar. 2017.

Education Sector Strategy Update : Achieving education for all, broadening our perspective, maximizing our effectiveness. December 22, 2005 (Final Draft). Washington, D.C.: The World Bank Group, 2005. Disponível em: <http://siteresources.worldbank.org/ EDUCATION/Resources/ESSU/Education_Sector_Strategy_Update.pdf>. Acesso em: 18 mar. 2017.

\section{Notas}

1 De acordo com a Resolução n 510 do Plenário do Conselho Nacional de Saúde, de 07 de abril de 2016, que em seu Parágrafo Único dispõe que: "Não serão registradas nem avaliadas pelo sistema CEP/CONEP: (...) VII - pesquisa que objetiva o aprofundamento teórico de situações que emergem espontanea e contingencialmente na prática profissional, desde que não revelem dados que possam identificar o sujeito“ (BRASIL, 2016).

2 A exposição e análise da Reforma Universitária sob o Governo de Lula da Silva encontra-se publicada em Leite (2010). Aqui, este fragmento comparece revisto, ampliado e atualizado.

3 Em todas as universidades federais, canteiros de obras inteiros jazem com esqueletos de prédios inacabados, pois o dinheiro foi estancado sem maiores explicações ou avisos.

4 Aeste respeito, ver ANDES (2007), em especial a Parte 3, REUNI, Universidade Nova e Professor Equivalente: faces da Reforma Universitária.

5 As variações de idade não foram analisadas neste estudo, pois demandariam uma metodologia que contemplasse as características próprias das modificações atinentes à idade (envelhecimento). Asua inserção na universidade (somente graduação, ou graduação e pós-graduação) será analisada em outro estudo.

\section{Janete Luzia Leite}

janeteluziaufrj@gmail.com

Doutorado em Serviço Social pela Universidade Federal do Rio de Janeiro (UFRJ)

Professora Associada da Escola de Serviço Social da Universidade Federal do Rio de Janeiro (UFRJ)

\section{UFRJ}

Avenida Pasteur, 250, Praia Vermelha

Rio de Janeiro - Rio de Janeiro - Brasil

CEP: 22.290-240 